\title{
Evaluation of the factors predicting the need for intensive care of patients with COVID-19 aged above 65 years: data from an emergency department in Turkey
}

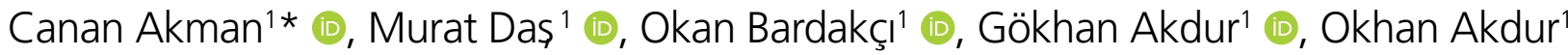

\section{SUMMARY}

OBJECTIVE: Individuals aged $\geq 65$ years are more susceptible to COVID-19 disease and admission to intensive care is most notable. The scoring systems (national early warning score, quick sequential organ failure assessment, shock index) are recommended for rapid assessment of patients in emergency room conditions. The goal of our study is to evaluate scoring systems in conjunction with predictive factors of need for admission to intensive care of patients $\geq 65$ years old with a diagnosis of COVID-19 who applied to the emergency room. METHODS: Patients were divided into two groups according to evolution in the emergency room, being those who needed or not intensive care. National Early Warning Score, quick sequential organ failure assessment, shock index scores and serum biochemistry, blood count and blood gas values were evaluated from hospital information management system records.

RESULTS: Of the patients included in the study, $80.8 \%$ were admitted to the ward and $14.5 \%$ to the unit of intensive care. Lymphocyte count, base deficit and bicarbonate levels were lower, and the levels of C-reactive protein, lactate, D-dimer, urea and lactate dehydrogenase were higher in patients who needed intensive care. Quick sequential organ failure assessment and shock index were considered significant in the group admitted to the intensive care unit.

CONCLUSIONS: We recommend that quick sequential organ failure assessment and shock index be used quickly, practically and easily in predicting the need for intensive care unit in patients aged $\geq 65$ years in emergency department diagnosed with COVID-19.

KEYWORDS: Age factors. Emergency medical services. Intensive care units.

\section{INTRODUCTION}

Coronavirus-19 (COVID-19) disease is an infectious disease caused by severe acute respiratory syndrome coronavirus- 2 $\left(\right.$ SARS-CoV-2) ${ }^{1,2}$. Studies show that individuals aged $\geq 65$ years are more susceptible to COVID-19 disease and have higher rates of hospital, intensive care, intubation, postintubation complications, and death ${ }^{3-6}$. Regarding the comorbid diseases, weak immune system also plays a role in increasing the sensitivity ${ }^{7,8}$. COVID-19, which develops with atypical symptoms, progresses to multiorgan failure within this age group 9 . It is noteworthy that admissions to the intensive care unit (ICU) are often the patients aged above 65 years $^{10}$. A number of scoring systems have been developed to rapidly evaluate the patients with COVID-19 admitted to the emergency department. It has

${ }^{1}$ Canakkale Onsekiz Mart University, School of Medicine, Department of Emergency Medicine - Canakkale, Turkey.

*Corresponding author: drcananakman@gmail.com

Conflicts of interest: the authors declare there are no conflicts of interest. Funding: none.

Received on July 14, 2021. Accepted on August 14, 2021. 
been stated that the National Early Warning Score (NEWS) in patients who are admitted to emergency department can reveal accurate results in both mortality within the hospital and hospitalization of patients from the emergency department to the ICU $^{11}$. Quick Sequential Organ Failure Assessment (q-SOFA) is recommended as it provides a rapid prognosis to emergency department and critical care doctors and helps predict mortality $^{12}$. The shock index (SI) can be used to predict mortality and the need for intensive care ${ }^{13}$. This study aims to determine the factors that predict the hospitalization of patients who aged above 65 years and diagnosed with COVID-19 in the emergency department and to evaluate those factors using the abovementioned scoring and indices.

\section{METHODS}

\section{Study design}

The study was planned retrospectively and was started after the approval of the ethics committee (dated: February 5, 2021, No. 2021-01). The patients with a diagnosis of COVID-19 who were hospitalized to the emergency department of the university hospital between June 2020 and February 2021 were included in this study. Demographic findings, vital signs, serum biochemistry, hemogram, and blood gas values of the patients were analyzed. The NEWS, q-SOFA score, and SI were used to assess the severity of patient with COVID-19. The patients were divided into two groups, namely, patients who need intensive care and those who do not, according to the outcome of the emergency department.

\section{Patients}

The patients with positive polymerase chain reaction, aged above 65 years, and diagnosed with COVID- 19 were included in this study. The patients aged above 65 years, trauma patients, the patients who were not diagnosed with COVID-19, and whose information could not be obtained from the system were excluded from the study.

\section{Laboratory analysis}

Serum biochemistry analyses were performed using colorimetric method in the 501 module of the Roche Cobas 6000 device, the hemogram analyses with the electrical impedance method in the Beckman Coulter DXH 800 device, and the blood gas values were examined using ISE (ion-selective electrode) potentiometric method in the radiometer ABL 800 device.

\section{Statistical analysis}

Mann-Whitney U test was used for numerical variables and chi-square test for comparison of categorical variables.
Logistic regression analysis was applied to predict ICU admission. A base model was created using the data with statistical significance in the multivariable analysis. The DeLong test was used for a pairwise comparison of the area under the curves ${ }^{14}$. SPSS version 26.0 was used for statistical analysis.

\section{RESULTS}

A total of 400 patients aged above 65 years and diagnosed with COVID-19 were included in the study. The mean age was 73 (interquartile range [IQR]: 68.0-80.75), and 229 (57.3\%) patients were males. Demographic, laboratory parameters, and other characteristics of the patients are indicated in Table 1.

Comparing the groups with and without ICU hospitalization in terms of gender and the emergency department outcome, the NEWS was not significantly different between the two groups ( $\mathrm{p}=0.630$ ), while $\mathrm{q}-\mathrm{SOFA}$ and SI were found to be significantly higher in the ICU group than the non-ICU groups $(\mathrm{p}<0.001)$, as given in Table 2 .

The relationship between risk factors and mortality in patients with COVID-19 is given in Table 3 .

\section{DISCUSSION}

In a study by Lee et al..$^{15}$ in patients aged above 65 years with a diagnosis of COVID-19, the median age was 72 and the majority were females ${ }^{15}$. Jin et al. ${ }^{16}$ and Jansen et al. ${ }^{17}$ showed that elderly males are more affected by COVID-19 infection than females. Elderly male gender is more prone to COVID-19 disease ${ }^{18}$. The mean age ( 73 years) and the predominance of male gender in our study correlate with the literature. The most common comorbid diseases in the elderly are hypertension (HT), cardiovascular diseases, diabetes mellitus (DM), chronic obstructive pulmonary disease, and hyperlipidemia ${ }^{19}$. In our study, HT and DM were found to be underlying comorbid diseases. Most common drugs related to these diseases used by the patients are antiplatelet and angiotensin-converting enzyme (ACE) inhibitors. HT is the most common comorbid disease diagnosed among the elderly patients. It was found that the use of drugs affecting the renin-angiotensinaldosterone (RAS) system, due to the ability of COVID-19 disease to enter the host cell by binding to ACE-2, increases the sensitivity to COVID-19 and causes viral replication ${ }^{20,21}$. In our study, the hospitalization rate of the patients aged above 65 years and diagnosed with COVID-19 was high. This finding is in line with many other studies in the literature $e^{3-6}$. Only $3.5 \%$ of the patients were discharged from the emergency department. It was found that the more severe the COVID-19, the higher is the mortality and the need for intensive care in the elderly patients ${ }^{4}$. In China and Italy, most mortality cases are with the patients aged above 
Table 1. Demographic parameters for study population.

\begin{tabular}{l|c} 
& All patients $(\mathrm{n}=400)$ \\
\hline Age & $73.0(68.0-80.75)$ \\
\hline Sex/male, $\mathrm{n}(\%)$ & $229(57.3)$ \\
\hline Vital signs at triage & \multicolumn{1}{|c}{} \\
\hline Heart rate (beat/min) & $87.0(77.0-99.0)$ \\
\hline Respiratory rate & $22.0(18.0-24.0)$ \\
\hline SBP $(\mathrm{mm} \mathrm{Hg})$ & $130.5(115.0-147.0)$ \\
\hline DBP $(\mathrm{mm} \mathrm{Hg})$ & $78.0(68.0-98.0)$ \\
\hline SO $(\%)$ & $95.0(90.0-98.0)$ \\
\hline Chronic diseases, $\mathrm{n}(\%)$ & \\
\hline HT & $258(64.5)$ \\
\hline DM & $115(28.8)$ \\
\hline COPD & $73(18.3)$ \\
\hline CAD & $78(19.5)$ \\
\hline Stroke & $36(9.0)$ \\
\hline Cancer & $28(7.0)$ \\
\hline CHF & $33(8.3)$ \\
\hline CRD & $20(5.0)$ \\
\hline Drg use $n(\%)$ & \\
\hline
\end{tabular}

\begin{tabular}{l|c}
\hline Drug use, $\mathrm{n}(\%)$ & $102(25.5)$ \\
\hline Antiplatelet & $92(23.0)$ \\
\hline ACE inhibitors & $81(20.3)$ \\
\hline Oral anticoagulants & \\
\hline
\end{tabular}

\begin{tabular}{l|c}
\hline Laboratory parameters & \\
\hline Lymphocyte & $1.0(0.6-1.6)$ \\
\hline C-reactive protein & $7.68(3.36-15.67)$ \\
\hline D-Dimer & $474.5(279.25-940.75)$ \\
\hline aPTT & $29.0(25.9-32.0)$ \\
\hline INR & $1.12(1.03-1.24)$ \\
\hline ALT & $19.0(12.0-29.97)$ \\
\hline AST & $28.6(19.75-42.78)$ \\
\hline Urea & $49.6(35.62-78.03)$ \\
\hline Creatinine & $1.07(0.82-1.54)$ \\
\hline LDH & $326.0(245.25-457.0)$ \\
\hline Base deficit & $-0.1(-2.6,2.3)$ \\
\hline Bicarbonate & $24.2(22.3-26.1)$ \\
\hline Shock index & $0.67(0.57-0.78)$ \\
\hline NEWS $\geq 10(\%)$ & $71(17.8)$ \\
\hline q-SOFA $\geq 2(\%)$ & $61(15.3)$ \\
\hline
\end{tabular}

Table 1. Continuation.

All patients $(n=400)$

Disposition, $\mathrm{n}(\%)$

\begin{tabular}{l|c}
\hline Discharge & $14(3.5)$ \\
\hline Regular ward & $323(80.8)$ \\
\hline ICU & $58(14.5)$ \\
\hline Exitus in the ED & $5(1.25)$ \\
\hline 14-Day mortality & $79(19.8)$ \\
\hline 30-Day mortality & $114(28.5)$ \\
\hline
\end{tabular}

SBP: systolic blood pressure; DBP: diastolic blood pressure; HT: hypertension; DM: diabetes mellitus; COPD: chronic obstructive pulmonary disease; CAD: coronary artery disease; CHF: congestive heart failure; CRD: chronic respiratory disease; ACE: angiotensin-converting enzyme; aPTT: activated partial thromboplastin time; INR: international normalized ratio; ALT: alanine transaminase; AST: aspartate aminotransferase; LDH: lactate dehydrogenase; NEWS: national early warning score; q-SOFA: quick sequential organ failure assessment; ICU: intensive care unit; ED: emergency department.

60 years. Age plays a key role in the estimation of mortality ${ }^{15,22}$. It is suggested that old age is a risk factor for in-hospital deaths, is more sensitive to COVID-19 disease, and can have severe courses'. Comparing the 14- and 30-day mortality rates, this study found that mortality increases with an increase in the length of stay in the ICU. Studies also reveal that staying in the ICU with respiratory support for a long time increases mortality ${ }^{20}$. Ji et al. ${ }^{23}$ stated that the number of ICU admissions were higher in the males aged above 65 years with an underlying comorbid disease ${ }^{23}$. In our study, there was no difference in terms of gender and the presence and number of comorbid diseases between patients who were admitted to the ICU and those who were not.

Vital signs play a key role in the early evaluation of patients diagnosed with COVID-19 and determination of whether the patients are at risk and require ICU admission ${ }^{24}$. In a study conducted on 2566 patients with an average age of 63, Hao et al..$^{25}$ found that there was no difference in respiratory rate, heart rate, and mean arterial pressure between the patients hospitalized in the ICU and those who were not ${ }^{25}$. In our study, systolic blood pressure, low oxygen saturation, and increased heart rate were found to be significant in terms of hospitalization in the ICU. Huang et al. ${ }^{10}$ and Wang et al. ${ }^{26}$ reported that dyspnea symptoms were more common in the patients admitted to ICU than in nonadmitted patients; the finding that is in line with our results. Liu et al. stated that in the patients aged above 60 years with COVID-19, the lymphocyte ratio was low and the C-reactive protein (CRP) level was high. Laboratory findings of elderly patients with COVID-19 also showed lymphopenia and high levels of CRP, lactate dehydrogenase (LDH), 
Table 2. Demographic findings.

\begin{tabular}{|c|c|c|c|}
\hline & Other, $n=342$ & ICU admission, $\mathrm{n}=58$ & p-value \\
\hline Age & $73.0(68.0-80.0)$ & $75(69.0-81)$ & \\
\hline Sex: M/F, n (\%) & $195(85.2) / 147(86.0)$ & $34(14.8) / 24(14.0)$ & 0.819 \\
\hline \multicolumn{4}{|l|}{ Triage parameter } \\
\hline SBP & $132.0(118.0-147.25)$ & $116.5(95.75-145.5)$ & 0.002 \\
\hline $\mathrm{DBP}$ & $78.0(69.0-87.0)$ & $74.0(64.0-85.75)$ & 0.136 \\
\hline Heart rate & $86.0(77.0-98.0)$ & $99.5(84.25-123.5)$ & $<0.001$ \\
\hline Respiratory rate & $22.0(18.0-24.0)$ & $22.0(18.0-26.0)$ & 0.396 \\
\hline Oxygen saturation & $95.0(91.0-98.0)$ & $90.5(81.5-97.25)$ & 0.004 \\
\hline \multicolumn{4}{|l|}{ Chronic disease, n (\%) } \\
\hline None & $35(77.8)$ & $10(22.2)$ & \multirow{3}{*}{0.161} \\
\hline 1 & $102(89.5)$ & $12(10.5)$ & \\
\hline 2 and above & $205(85.1)$ & $36(14.9)$ & \\
\hline \multicolumn{4}{|l|}{ Mortality status, n (\%) } \\
\hline Yes $(n=127)$ & $87(68.5)$ & $40(31.5)$ & \multirow{2}{*}{$<0.001$} \\
\hline No $(n=273)$ & $255(93.4)$ & $18(6.6)$ & \\
\hline \multicolumn{4}{|c|}{ Complaints at the ED admission, $\mathrm{n}(\%)$} \\
\hline Fever $( \pm)$ & 239 (83.9)/103 (89.6) & $46(16.1) / 12(10.4)$ & 0.142 \\
\hline Cough $( \pm)$ & $217(81.3) / 125$ (94.0) & $50(18.7) / 8(6)$ & 0.001 \\
\hline Dyspnea $( \pm)$ & $161(95.8) / 181(78.0)$ & $7(4.2) / 51(22.0)$ & $<0.001$ \\
\hline Headache $( \pm)$ & $323(85.0) / 19(95.0)$ & $57(15.0) / 1(5.0)$ & 0.216 \\
\hline Fatigue $( \pm)$ & $276(83.6) / 66(94.3)$ & $54(16.4) / 4(5.7)$ & 0.022 \\
\hline Anosmia $( \pm)$ & $331(86.2) / 11(68.8)$ & $53(13.8) / 5(31.3)$ & 0.052 \\
\hline Diarrhea $( \pm)$ & $325(84.9) / 17(100)$ & $58(15.1) / 0(0.0)$ & 0.149 \\
\hline Joint pain $( \pm)$ & $300(84.3) / 42(95.5)$ & $56(15.7) / 2(4.5)$ & 0.066 \\
\hline \multicolumn{4}{|l|}{ Laboratory parameter } \\
\hline Lymphocyte & $1.0(0.7-1.6)$ & $0.67(0.41-1.46)$ & 0.008 \\
\hline CRP & $7.32(3.2-14.73)$ & $8.69(4.15-21.08)$ & 0.021 \\
\hline Base deficit & $0.1(-2.3,2.43)$ & $-1.6(-8.95,1.5)$ & 0.002 \\
\hline Lactate & $1.6(1.14-2.23)$ & $2.25(1.47-2.97)$ & $<0.001$ \\
\hline Bicarbonate & $24.4(22.8-26.2)$ & $21.55(16.5-25.4)$ & $<0.001$ \\
\hline D-Dimer & $433.0(276.0-778.0)$ & $982.0(439.0-2838.0)$ & $<0.001$ \\
\hline Urea & $48.55(35.2-72.0)$ & $69.4(42.3-117.4)$ & $<0.001$ \\
\hline Creatinine & $1.03(0.82-1.49)$ & $1.25(0.83-1.83)$ & 0.098 \\
\hline LDH & $324.5(243.0-433.0)$ & $374.5(255.0-586.0)$ & 0.018 \\
\hline \multicolumn{4}{|l|}{ NEWS, n (\%) } \\
\hline$\leq 10$ point & $280(85.1)$ & $49(14.9)$ & \multirow{2}{*}{0.630} \\
\hline 11 and above & $62(87.3)$ & $9(12.7)$ & \\
\hline \multicolumn{4}{|l|}{ q-SOFA, n (\%) } \\
\hline 0-1 point & 317 (93.5) & $22(6.5)$ & \multirow{2}{*}{$<0.001$} \\
\hline $2-3$ points & $25(41.0)$ & $36(59.0)$ & \\
\hline Shock index & $0.65(0.57-0.76)$ & $0.85(0.69-1.14)$ & $<0.001$ \\
\hline
\end{tabular}

M: male; F: female; SBP: systolic blood pressure; DBP: diastolic blood pressure; ED: emergency department; CRP: C-reactive protein; LDH: lactate dehydrogenase; NEWS: national early warning score; q-SOFA: quick sequential organ failure assessment. 
Table 3. Association between risk factors and mortality in the patients with COVID-19 and pairwise comparisons of receiver operating characteristic curves.

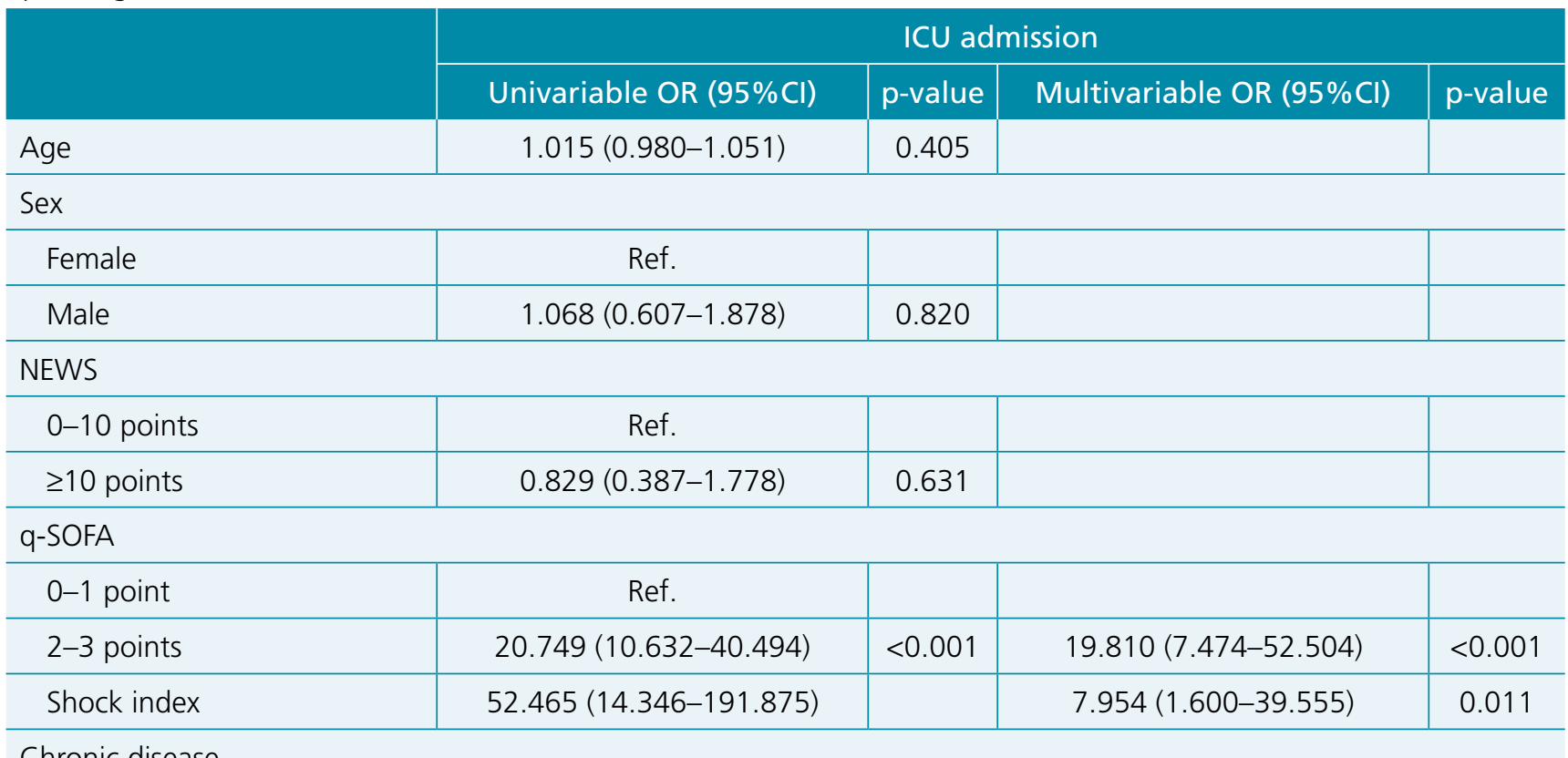

Chronic disease

\begin{tabular}{|c|c|c|c|c|c|c|c|}
\hline None & \multicolumn{2}{|l|}{ Ref. } & & & & & \\
\hline 1 & \multicolumn{2}{|l|}{$0.412(0.164-1.036$} & 0.060 & & & & \\
\hline 2 and above & \multicolumn{2}{|l|}{$0.615(0.280-1.350)$} & 0.225 & & & & \\
\hline \multicolumn{8}{|l|}{ Complaints at the ED admission } \\
\hline Cough & \multicolumn{2}{|l|}{$0.278(0.128-0.605)$} & 0.001 & & & & \\
\hline Dyspnea & \multicolumn{2}{|l|}{$6.481(2.860-14.686)$} & $<0.001$ & \multicolumn{3}{|c|}{$6.420(2.044-20.164)$} & 0.001 \\
\hline Fatigue & \multicolumn{2}{|l|}{$0.310(0.108-0.886)$} & 0.029 & & & & \\
\hline \multicolumn{8}{|l|}{ Laboratory parameter } \\
\hline Lymphocyte & \multicolumn{2}{|l|}{$1.000(0.970-1.030)$} & 0.995 & & & & \\
\hline CRP & \multicolumn{2}{|l|}{$1.038(1.010-1.068)$} & 0.008 & & & & \\
\hline Base deficit & \multicolumn{2}{|l|}{$0.896(0.853-0.942)$} & $<0.001$ & & & & \\
\hline Lactate & \multicolumn{2}{|l|}{$1.269(1.101-1.462)$} & 0.001 & & & & \\
\hline Bicarbonate & \multicolumn{2}{|l|}{$0.856(0.806-0.910)$} & $<0.001$ & & & & \\
\hline D-Dimer & \multicolumn{2}{|l|}{$1.000(1.000-1.000)$} & 0.025 & & & & \\
\hline Urea & \multicolumn{2}{|l|}{$1.012(1.007-1.017)$} & $<0.001$ & \multicolumn{3}{|c|}{$1.010(1.002-1.018)$} & 0.012 \\
\hline LDH & \multicolumn{2}{|l|}{$1.002(1.000-1.003)$} & 0.009 & & & & \\
\hline \multirow{3}{*}{ Prognostic model } & \multirow{3}{*}{$\begin{array}{l}\text { Area under the ROC } \\
\text { curve }(95 \% \mathrm{Cl})\end{array}$} & \multicolumn{6}{|c|}{ Pairwise analysis } \\
\hline & & \multirow{2}{*}{ DBA } & \multirow{2}{*}{ SE } & \multicolumn{2}{|c|}{$95 \% \mathrm{Cl}$} & \multirow{2}{*}{ Z-statistic } & \multirow{2}{*}{ p-value } \\
\hline & & & & Lower & Upper & & \\
\hline Base model=Dyspnea+SI+Urea & $0.825(0.760-0.883)$ & \multirow{2}{*}{0.058} & \multirow{2}{*}{0.236} & \multirow{2}{*}{0.022} & \multirow{2}{*}{0.093} & \multirow{2}{*}{3.180} & \multirow{2}{*}{0.001} \\
\hline Base model+q-SOFA & $0.883(0.830-0.936)$ & & & & & & \\
\hline
\end{tabular}

ICU: intensive care unit; OR: odds ratio; Cl: confidence interval; NEWS: national early warning score; q-SOFA: quick sequential organ failure assessment; ED: emergency department; CRP: C-reactive protein; LDH: lactate dehydrogenase; ROC: receiver operating characteristic; SE: standard error. 
and D-dimer ${ }^{4,27,28}$. In our study, unlike lymphopenia, base deficit and bicarbonate were found to be low. CRP, D-dimer, urea, and LDH levels were high, whereas lactate levels were high. These results were statistically significant, which are in line with the findings of the studies in the literature.

In the patients aged above 65 years with a diagnosis of COVID-19, the NEWS gave the most accurate score for both ICU admission and mortality estimation ${ }^{29}$. In our study, the NEWS was not significant for both groups. Due to the additional diseases of patients aged above 65 years and the reflection of these diseases on vital signs, it has been observed that it is as high in patients who are followed up in the service without the need for intensive care as in the patients in the ICU. In a retrospective study with patients with COVID-19, q-SOFA is recommended for the prediction of respiratory failure and mortality ${ }^{30}$. Doğanay et al. ${ }^{13}$ stated that the SI is a useful parameter for mortality prevention, early intervention, and hospitalization of elderly patients and patients with COVID-19 with low oxygen saturation ${ }^{13}$. In our study, the use of q-SOFA in patients aged above 65 years with SI was found to be more effective in the prediction of admission to the ICU.

\section{CONCLUSION}

In age group of ${ }^{3} 65$ years, q-SOFA, SI, dyspnea, and urea elevation are effective in predicting the need for intensive care.

\section{AUTHORS' CONTRIBUTIONS}

CA: Conceptualization, Data curation, Investigation, Methodology, Writing - original draft, Writing - review \& editing. MD: Conceptualization, Formal analysis, Methodology, Writing - original draft, Writing - review \& editing. OB: Investigation, Writing - original draft, Writing - review \& editing. GA: Conceptualization, Investigation, Writing - original draft, Writing - review \& editing. OA: Writing - review \& editing.

\section{REFERENCES}

1. Wu Z, Mc Googan JM. Characteristics of and important lessons from the corona virus disease 2019 (COVID-19) outbreak in China: summary of a report of 72314 cases from the Chinese center for disease control and prevention. JAMA. 2020;323(13):123942. https://doi.org/10.1001/jama.2020.2648

2. World Health Organization. Corona virus disease (COVID-19) pandemic. Geneva: World Health Organization; 2020. [cited on March 30, 2020]. Available from: https://www.who.int/ emergencies/diseases/novel-coronavirus-2019

3. Morley JE, Vellas B. Editorial COVID-19 and older adults. J Nutr Health Aging. 2020;24(4):364-5. https://doi.org/10.1007/ s12603-020-1349-9

4. Liu K, Chen Y, Lin R, Han K. Clinical features of COVID-19 in elderly patients: A comparison with young and middle-aged patients. J Infect. 2020;80(6):e14-8. https://doi.org/10.1016/j. jinf.2020.03.005

5. Liu Y, Mao B, Liang S, Yang JW, Lu HW, Chai YH, et al. Association between age and clinical characteristics and outcomes of COVID-19. Eur Respir J. 2020;55:2001112. https://doi.org/10.1183/13993003.01112-2020

6. Ho FK, Petermann-Rocha F, Gray SR, Jani BD, Katikireddi SV, Niedzwiedz CL, et al. Is older age associated with COVID-19 mortality in the absence of other risk factors? General population cohort study of 470,034 participants. PLoS One. 2020;15(11):e0241824. https://doi.org/10.1371/ journal.pone.0241824

7. Li Q, Guan X, Wu P, Wang X, Zhou L, Tong Y, et al. Early transmission dynamics in Wuhan, China, of novel corona virus-infected pneumonia. N Engl J Med. 2020;382(13):1199207. https://doi.org/10.1056/NEJMoa2001316

8. Mohamadi M, Goodarzi A, Aryannejad A, Fattahi N, AlizadehKhoei M, Miri S, et al. Geriatric challenges in the new coronavirus disease-19 (COVID-19) pandemic: a systematic review. Med J Islam Repub Iran. 2020;34:123. https://doi.org/10.34171/mjiri.34.123
9. Guo T, Shen Q, Guo W, He W, Li J, Zhang Y, et al. Clinical characteristics of elderly patients with COVID-19 in Hunan Province, China: a multicenter, retrospective study. Gerontology. 2020;66:467-75. https://doi.org/10.1159/000508734

10. Wang D, Hu B, Hu C, Zhu F, Liu X, Zhang J, et al. Clinical characteristics of 138 hospitalized patients with 2019 novel Coronavirus-Infected pneumonia in Wuhan, China. JAMA. 2020;323(11):1061-9. https://doi.org/10.1001/jama.2020.1585

11. Liao $X$, Wang B, Kang $Y$. Novel corona virus infection during the 2019-2020 epidemic: preparing intensive care units-the experience in Sichuan Province, China. Intensive Care Med. 2020;46(2):357-60. https://doi.org/10.1007/s00134-020-05954-2

12. Vincent JL, Moreno R, Takala J, Willatts S, Mendonça A, Bruining $H$, et al. The SOFA (Sepsis-related Organ Failure Assessment) score to describe organ dysfunction/failure. On behalf of the Working Group on Sepsis-related problems of the European Society of Intensive Care Medicine. Intensive Car Med.1996;22(7):707-10. https://doi.org/10.1007/BF01709751

13. Doğanay F, Elkonca F, Seyhan AU, Yılmaz E, Batırel A, Ak R. Shock index as a predictor of mortality among the Covid-19 patients. Am J Emerg Med. 2021;40:106-9. https://doi. org/10.1016/j.ajem.2020.12.053

14. Long ER, Long DM, Clarke-Pearson DL. Comparing the areas under two or more correlated receiver operating characteristic curves: a nonparametric a approach. Biometrics. 1988;44(3):837-45. http://doi.org/10.2307/2531595

15. Lee JY, Kim HA, Huh K, Hyun M, Rhee J-Y, Jang $S$, et al. Risk factors for mortality and respiratory support in elderly patients hospitalized with COVID-19 in Korea. J Korean Med Sci. 2020;35(23):e223. https://doi.org/10.3346/jkms.2020.35.e223

16. Jin J-M, Bai P, He W, Wu F, Liu X-F, Han D-M, et al. Gender differences in patients with COVID-19: focus on severity and mortality. Front Public Health. 2020;8:152. https://doi. org/10.3389/fpubh.2020.00152 
17. Jansen A, Chiew M, Konings F, Lee CK, Ailan L, on behalf the World Health Organization Regional Office for the Western Pacific MERS Event Management Team. Sex matters - a preliminary analysis of Middle East respiratory syndrome in the Republic of Korea, 2015. Western Pac Surveil Response J. 2015;6(3):68-71. https://doi.org/10.5365/NPSAR.2015.6.3.002

18. Walter LA, MCGregor AJ. Sex-and gender-specific observations and implications for COVID-19. West J Emerg Med. 2020;21(3):507-9. https://doi.org/10.5811/ westjem.2020.4.47536

19. Neumann-Podczaska A, Al-Saad SR, Karbowski LM, Chojnicki M, Tobis S, Wieczorowska-Tobis K. COVID 19 - clinical picture in the elderly population: a qualitative systematic review. Aging Dis. 2020;11(4):988-1008. https://doi.org/10.14336/ AD.2020.0620

20. Grasselli G, Greco M, Zanella A, Albano G, Antonelli M, Bellani $G$, et al. Risk factors associated with mortality among patients with COVID-19 in Intensive Care Units in Lombardy, Italy. JAMA Intern Med. 2020;180(10):1345-55. https://doi. org/10.1001/jamainternmed.2020.3539

21. Schiffrin EL, Flack JM, Ito S, Muntner P, Webb RC. Hypertension and COVID-19. Am J Hypertens. 2020;33:373-4. https://doi. org/10.1093/ajh/hpaa057

22. Dhama K, Patel SK, Kumar R, Rana J, Yatoo MI, Kumar A, et al. Geriatric population during the COVID-19 pandemic: problems, considerations, exigencies, and beyond. Frontiers in Public Health. 2020;8:574198. https://doi.org/10.3389/ fpubh.2020.574198

23. Ji D, Zhang D, Xu J, Chen Z, Yang T, Zhao P, et al. Prediction for progression risk in patients with COVID-19 pneumonia: the CALL score. Clin Infect Dis. 2020;71:1393-9. https://doi. org/10.1093/cid/ciaa414
24. Sands KE, Wenzel RP, McLean LE, Korwek KM, Roach JD, Miller KM, et al. Patient characteristics and admitting vital signs associated with coronavirus disease 2019 (COVID-19) - related mortality among patients admitted with noncritical illness. Infect Control Hosp Epidemiol. 2021;42(4):399-405. https://doi.org/10.1017/ice.2020.461

25. Hao B, Sotudian S, Wang T, Xu T, Hu Y, Gaitanidis A, et al. Early prediction of level-of-care requirements in patients with COVID19. Elife. 2020;9:e60519. https://doi.org/10.7554/eLife.60519

26. Huang C, Wang Y, Li X, Ren L, Zhao J, Hu Y, et al. Clinical features of patients infected with 2019 novel corona virus in Wuhan, China. The Lancet. 2020;395(10223):497-506. https://doi.org/10.1016/S0140-6736(20)30183-5

27. Chen T, Dai Z, Mo P, Li X, Ma Z, Song S, et al. Clinical characteristics and outcomes of older patients with coronavirus disease 2019 (COVID-19) in Wuhan, China: a singlecentered, retrospective study. J Gerontol A Biol Sci Med Sci. 2020;75(9):1788-95. https://doi.org/10.1093/gerona/glaa089

28. Godaert L, Proye E, Demoustier-Tampere D, Coulibaly PS, Hequet F, Dramé M. Clinical characteristics of older patients: the experience of a geriatric short-stay unit dedicated to patients with COVID-19 in France. J Infect. 2020;81(1):e93-4. https://doi.org/10.1016/j.jinf.2020.04.009

29. ChenT, Wu D, Chen H, Yan W, Yang D, Chen G, et al. Clinical characteristics of 113 deceased patients with corona virus disease 2019: retro spective study. BMJ. 2020;368:m1091. https://doi.org/10.1136/bmj.m1091

30. Lalueza A, Laro-Tamayo J, de la Calle C, Sayas-Catalán J, Arrieta E, Maestro $G$, et al. The early use of sepsis scores to predict respiratory failure and mortality in non-ICU patients with COVID-19. Rev Clin Esp. 2020. https://doi.org/10.1016/j.rceng.2020.10.004 